\title{
Port-Site Metastasis after Laparoscopic Surgery with Rapid Second Recurrence in Early Stage Endometrial Carcinoma: A Case Report and Review of the Literature
}

\author{
Zoulikha Outaggarts $^{1 *}$, Sarah Johnstone ${ }^{1,2}$, Annekathryn Goodman ${ }^{1,3}$ \\ ${ }^{1}$ Harvard Medical School, Boston, USA \\ ${ }^{2}$ Department of Pathology, Massachusetts General Hospital, Boston, USA \\ ${ }^{3}$ Department of Obstetrics and Gynecology, Massachusetts General Hospital, Boston, USA \\ Email: zoulikha.outaggarts@student.uni-tuebingen.de
}

Received 5 May 2015; accepted 14 June 2015; published 17 June 2015

Copyright (C) 2015 by authors and Scientific Research Publishing Inc.

This work is licensed under the Creative Commons Attribution International License (CC BY).

http://creativecommons.org/licenses/by/4.0/

(c) (i) Open Access

\section{Abstract}

Introduction: Port site metastases have been reported with laparoscopic surgery. The mechanism of action is unknown. Theories include tumor tracking, spillage, pneumoperitoneum, and immune factors. Methods: We report on a case of aggressive port site metastases and intra-abdominal recurrence after an uncomplicated laparoscopic hysterectomy for a grade 2 , minimally invasive endometrioid adenocarcinoma of the uterus. The world literature on port site metastases in gynecological cancer is reviewed. Results: Port site metastases have two distinct presentations. In the first pattern, the metastases are isolated to the laparoscopic port sites. In the second pattern, port site metastases are associated with widespread intra-abdominal recurrence. Conclusion: Port site metastases are rare but occur with laparoscopic surgery. Meticulous attention to surgical technique including the use of specimen bags to isolate tissue and prevent spillage should be performed. Data registries should be instituted to track the incidence and outcomes of port site metastases.

\section{Keywords}

Port Site Metastases, Laparoscopic Hysterectomy, Endometrial Cancer

\section{Introduction}

With the increasing use of laparoscopic surgical techniques to remove the uterus and adnexa in gynecologic

${ }^{*}$ Corresponding author.

How to cite this paper: Outaggarts, Z., Johnstone, S. and Goodman, A. (2015) Port-Site Metastasis after Laparoscopic Surgery with Rapid Second Recurrence in Early Stage Endometrial Carcinoma: A Case Report and Review of the Literature. Open Journal of Obstetrics and Gynecology, 5, 324-332. http://dx.doi.org/10.4236/ojog.2015.56047 
cancers, there has been concern that these techniques could alter the natural history of these malignancies by mechanically spreading tumor cells. Tumor implantation in the laparoscopic trocar or port incisions, called "port site metastases” (PSM), has been reported in both multiple case reports and case series. PSM could also occur in the trocar sites which were not used for removing specimens [1]. In a large study with 1694 patients, who underwent laparoscopic surgeries for malignant gynecological cancers, 20 patients (1.18\%) developed port-site metastases [2]. Fifteen of them had ovarian or fallopian tube carcinoma and only one patient had uterine cancer [2]. In another report of 295 patients who underwent laparoscopy for endometrial cancer, one patient developed $\operatorname{PSM}(0.33 \%)$ [3].

The incidence of port site metastases is frequently associated with other sites of recurrence, and most patients with port site metastases carry a diagnosis of ovarian cancer. In contrast, only eight cases of port-site metastasis along with intra-abdominal recurrence after surgery for endometrial cancer have been reported in literature [4].

We describe a patient who developed a rapid recurrence of a minimally invasive, low to intermediate-grade endometrial cancer. The literature on PSM after laparoscopic surgery for malignancies and possible mechanisms of tumor spread in minimally invasive surgery are reviewed.

\section{Case Report}

The Patient is a 62-year-old, gravida 2, para 2 woman with BMI of $43.6 \mathrm{~kg} / \mathrm{m}^{2}$. She was not on hormone replacement therapy. Figure 1 and Table 1 summarize her clinical course. She presented with vaginal bleeding.

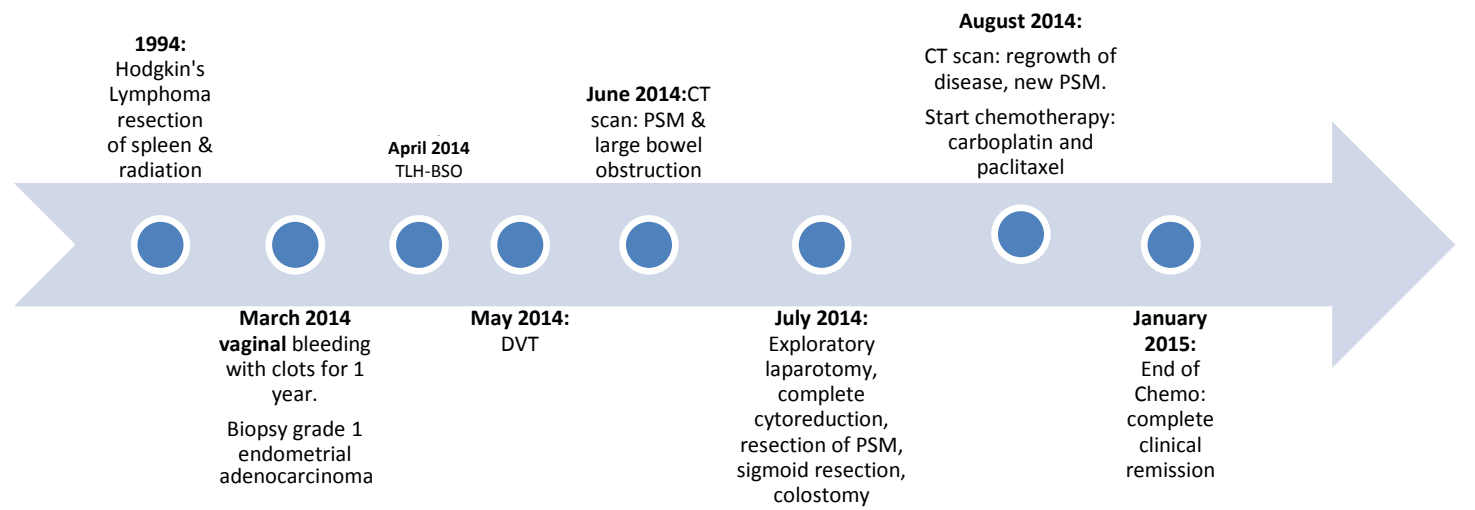

DVT: deep vein thrombosis; PSM port site metastases; TLH-BSO: total laparoscopic hysterectomy, bilateral salpingo-oophorectomy.

Figure 1. Clinical summary.

Table 1. Summary of oncologic history.

\begin{tabular}{|c|c|}
\hline Date & Event \\
\hline 1994 & Treatment of Hodgkin’s Lymphoma by splenectomy, chemotherapy, and radiation. \\
\hline March 2014 & $\begin{array}{l}\text { Development of one year of menometrorrhagia. Biopsy: grade } 1 \text { endometrial adenocarcinoma. Cervical cytology: normal. } \\
\text { Pelvic ultrasound: } 12 \times 6.2 \times 6.2 \mathrm{~cm} \text { uterus. Endometrial stripe was } 3 \mathrm{~cm} \text {. }\end{array}$ \\
\hline April 2014 & $\begin{array}{l}\text { Total laparoscopic hysterectomy, Bilateral salpingo-oophorectomy, lysis of adhesion, release of incarcerated hernia } \\
\text { (Figure 5(a)), omentectomy, cystoscopy and ventral hernia repair. } \\
\text { Pathology: Grade } 2 \text { endometrioid adenocarcinoma (Figure } 2 \text { and Figure 3). }\end{array}$ \\
\hline May 2014 & Development of left subclavian and internal jugular deep vein thrombosis. Treated with enoxaparin. \\
\hline June 2014 & Development of large bowel obstruction. Abdominal CT scan: port site metastases (Figures 5(b)-(d)). \\
\hline July 2014 & $\begin{array}{l}\text { Exploratory laparotomy and complete cytoreductive surgery, resection of port site metastases, sigmoid resection, colostomy } \\
\text { Finding: multiple port-site metastasis; omental disease; large tumor mass encasing and penetrating rectum and vagina; } \\
\text { plaque of tumor on the external surface of the bladder. No ascites, no peritoneal studding, no carcinomatosis. } \\
\text { Pathology: Grade } 2 \text { endometrioid adenocarcinoma (Figure 4). }\end{array}$ \\
\hline August 2014 & $\begin{array}{l}\text { Admission for pain control and wound infection. Abdominal CT scan: significant regrowth of her disease. } \\
\text { Patient received first dose of Carboplatin and Paclitaxel. }\end{array}$ \\
\hline January 2015 & $\begin{array}{l}\text { Completion of six cycles of Caboplatin and Paclitaxel. } \\
\text { Clinical remission: CA-125 marker was } 10 \mathrm{U} / \mathrm{ml} \text { (range } 0 \text { - 35) and a negative abdominal CT scan. }\end{array}$ \\
\hline May 2015 & No evidence of recurrence. \\
\hline
\end{tabular}


An endometrial biopsy revealed a grade 1 endometrial adenocarcinoma. She underwent an uncomplicated laparoscopic hysterectomy with bilateral salpingo-oophorectomy. One month postoperatively, she developed a deep vein thrombosis. She was treated with low molecular weight heparin as anticoagulation therapy. Three months after her hysterectomy, she presented with metastatic tumor in her port sites and a pelvic mass. She underwent an exploration, and fully cytoreductive surgery with excision of the pelvic tumor, upper vaginectomy, sigmoid resection, and end colostomy. One month later, she had evidence of tumor recurrence. Chemotherapy with carboplatin and paclitaxel was started. She received six cycles of chemotherapy with a complete resolution of tumor. She is currently disease-free at five months from completion of chemotherapy.

\section{Pathology}

April 2014: Final pathological diagnosis of April 2014: Endometrioid adenocarcinoma, grade 2 of 3, with limited superficial myometrial invasion to $1 \mathrm{~mm}$ and without cervical or vascular invasion. No diagnostic abnormalities were recognized in the ovaries, fallopian tubes and omentum (Figure 2 and Figure 3).

July 2014: Final pathological diagnosis of July 2014: In the skin and abdominal wall, fibrosis with foreign body giant cell reaction, fat necrosis, and mesh were diagnosed. Furthermore metastatic, adenocarcinoma consistent with known endometrial primary were diagnosed in the skin and abdominal wall, multiple abdominal wall

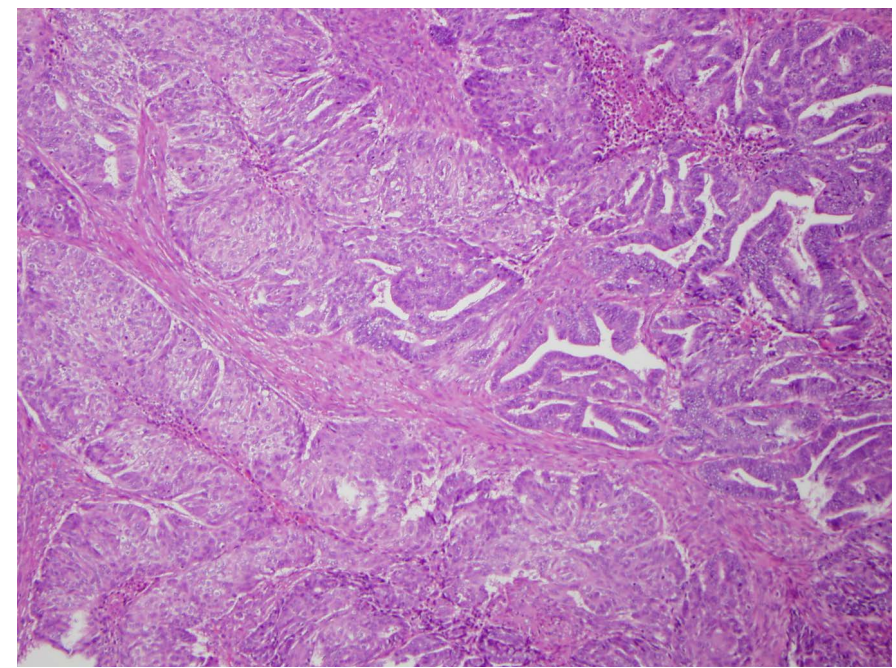

Figure 2. Grade 2 endometrioid adenocarcinoma with superficial invasion (10× magnification).

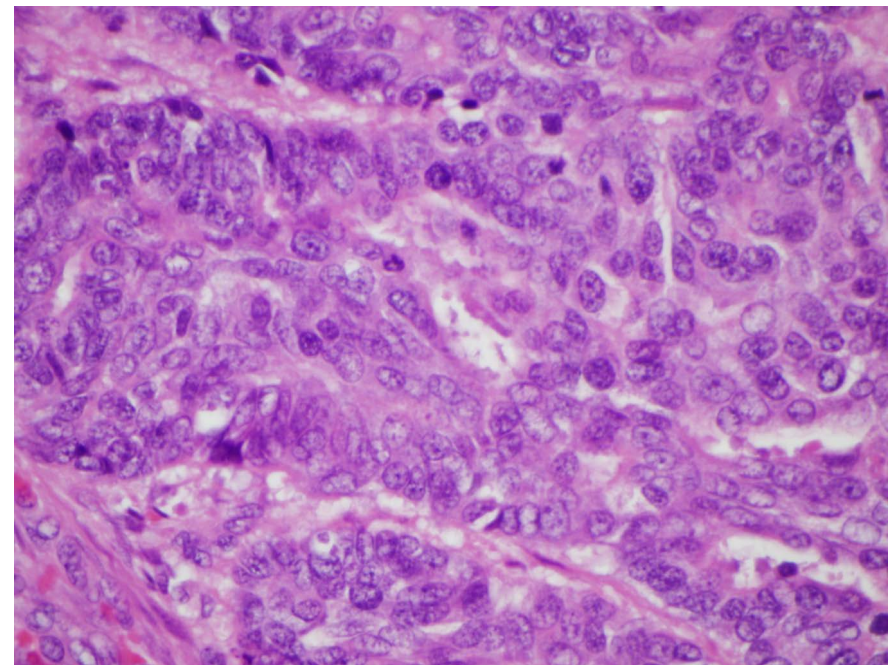

Figure 3. Grade 2 endometrioid adenocarcinma in the uterine specimen (50× magnification). 


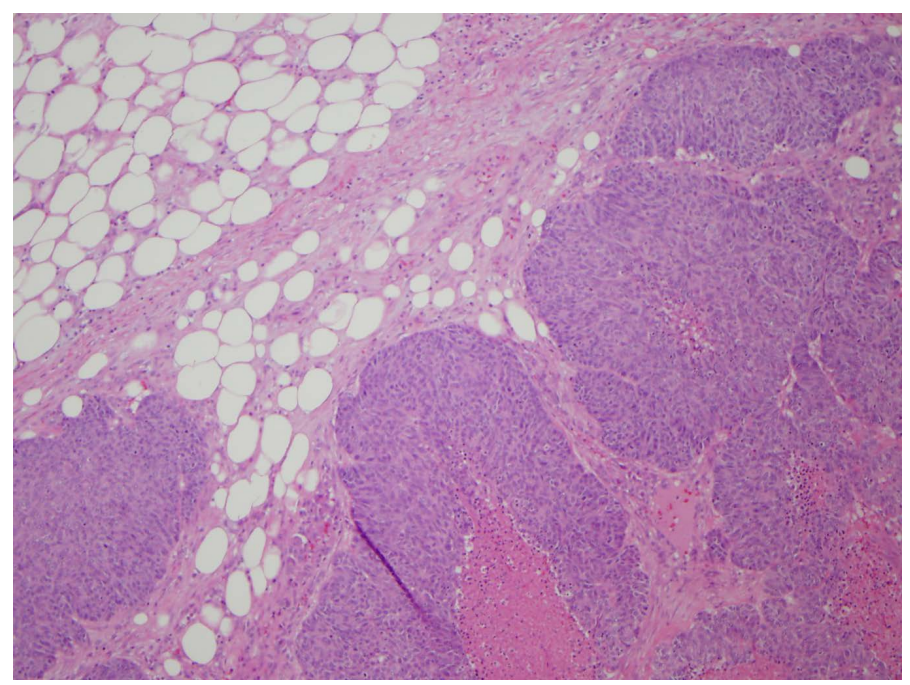

Figure 4. Abdominal wall portsite metastases.

nodules, omentum, bladder peritoneum and bladder, pelvic lymph nodes, vagina, rectosigmoid colon (extending through muscularis propria; colonic margins negative for tumor). Descending colon had no evidence of malignancy (Figure 4).

\section{Discussion}

The mechanism for port-site metastasis (PSM) development is unknown. The reports of PSM have raised the question of whether an environment that promotes tumor dissemination may be created by laparoscopically managed gynecological malignancies. Even for low grade cancers, there is a risk of tumor cell implantation. The main concern is whether port-site metastasis is iatrogenic or is driven by the tumor's biology, in which the tumor just does not behave as the FIGO criteria would predict. We report a very rare case of port site metastases along with intra-abdominal recurrence in an early stage endometrial cancer (FIGO Stage IA, G2), that developed within a very short time. The first PSM was diagnosed three months after primary laparoscopic surgery and the second PSM-recurrence developed one month after the second surgery which was a laparotomy.

\subsection{Review of the Literature}

Currently there have been twelve reported cases of PSM after total laparoscopic hysterectomy (TLH). Eight cases had non-isolated PSM and four cases involved isolated PSM, where there was no evidence of an association with peritoneum carcinomatosis [4] [5]. Table 2 summarizes the characteristics of reported PSM after laparoscopic hysterectomy.

Although in the present case there was no carcinomatosis, but because of the presence of several intra-abdominal metastasis, we consider this case to be a non-isolated port-site metastasis. Two other cases with highgrade carcinoma (IIIA, IIIC) show an even quicker rate of the PSM-development (1 month) [6], but they had no recurrence of the first PSM. Only one case of the twelve patients had a double PSM, despite an initial low-grade carcinoma (IA, G2) [7]. In comparison to all the other non-isolated cases, our patient had the lowest grade carcinoma and is the only patient who has both a second recurrence and a quick rate of PSM development.

\subsection{Clinical Significance}

According to the study of Zivanovic et al. where 1694 patients underwent laparoscopic surgeries for malignant gynecological cancers, our patient would have a bad prognosis because of the rapidity of her disease [2]. Their data showed that the only significant predictor of survival was the interval between laparoscopy and detection. Patients who developed port-site metastases within seven months from the laparoscopic surgery had a median survival of twelve months while patients who developed port-site metastasis after seven months had a median survival of 37 months $(\mathrm{P}=0.004)$. This study also demonstrates that of these 1694 patients, $20(1.18 \%)$ 


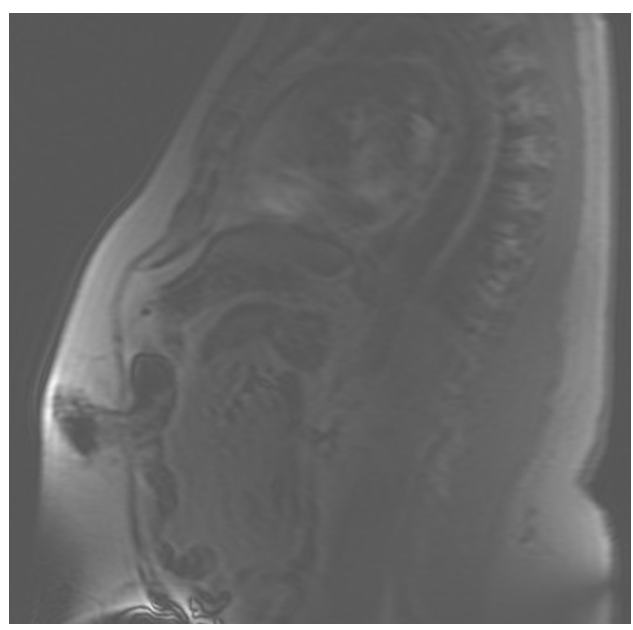

(a)

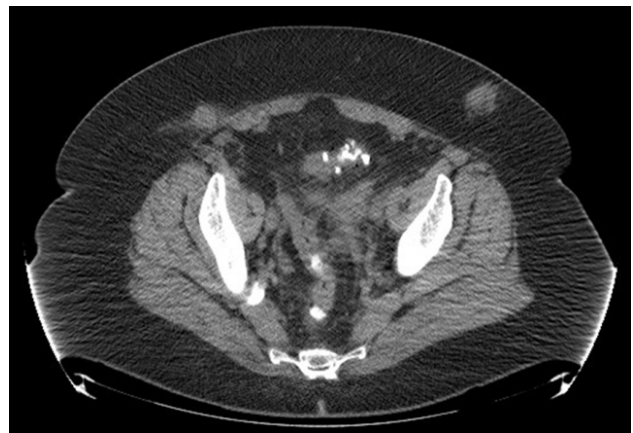

(b)

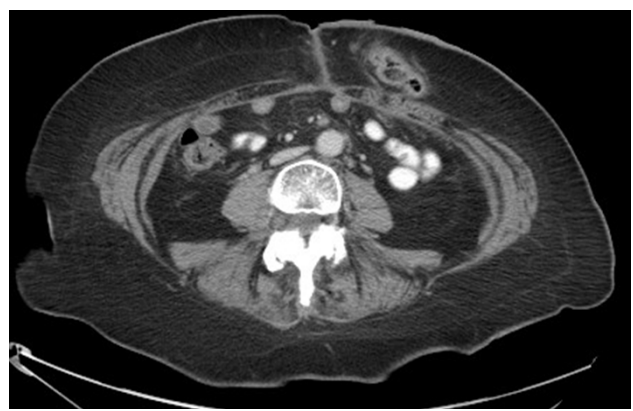

(c)

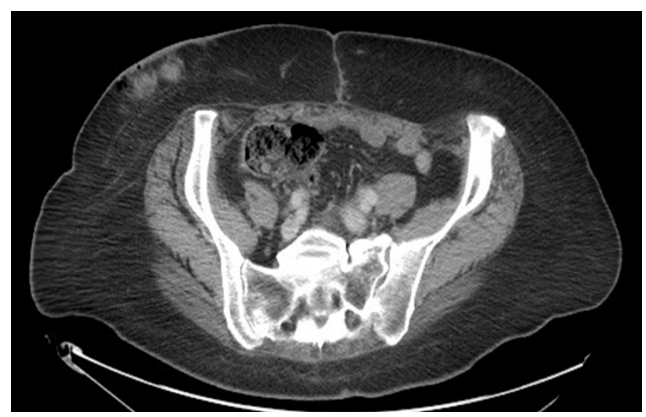

(d)

Figure 5. (a) Incarcerated hernia; (b)-(d) CT scan of the abdomen shows metastases in the subcutaneous tissue in the sites of the laparoscopic ports. 
Table 2. Summary of the published case reports with the present case.

\begin{tabular}{cccc}
\hline Characteristics & Isolated $(\mathrm{n}=4)[5][7]-[9]$ & Non-isolated $(\mathrm{n}=8)[2][3][6]$ [9]-[11] & Our patient \\
\hline FIGO stage & IA, G2-IIB, G2 & IC, G2-IV & IA, G2 \\
Onset of disease & $7-48$ months & $1-39$ months & 3 months \\
Survival & $5-42$ months & $11-53$ months & Median 12 months \\
Prognosis & Poor & Poor & Poor \\
\hline
\end{tabular}

developed port-site metastasis and 95\% of those patients (19 patients) had simultaneously port-site metastasis and metastasis to other sites or carcinomatosis. Their conclusion that PSM is a surrogate for advanced disease $[2]$.

According to the current data, our patient has three reasons for a poor prognosis. Not only due to her intra-abdonimal metastasis and the occurrence of both PSM in less than 7 months after her TLH, but also due to development of a deep vein thrombosis (DVT) just 1 month after her hysterectomy. DVT is a possible predictor of the presence of an advanced disease in cancer patients [12]. Sorensen et al. concluded that cancer diagnosed in less than one year after an event of venous thromboembolism is associated with an advanced stage of cancer and a poor prognosis [13].

In 1978, the first case report of a patient with ovarian carcinoma and ascites who developed PSM two weeks after laparoscopic surgery was reported. Current collective experience has demonstrated that PSM in gynecological malignancies occurs mostly in patients with ovarian cancer and in patients with intraperitoneal dissemination such as ascites or carcinomatosis [2] [14]. An explanation might be that the presence and possible leakage of ascites through the small abdominal incision leads to an increased contamination of these abdominal wall incisions by malignant cells [15]. Also, in other disciplines like in General Surgery and Urological Surgery, a patient with ascites or peritoneal carcinomatosis is considered as the high-risk patient for PSM [16].

\subsection{Laparotomy vs Laparoscopy}

There are several benefits of laparoscopic surgery compared to the open approach. These include fewer postoperative complications, reduced risk of morbidity, shorter hospital stays and a quicker recovery which allows the return to normal activities [17]. Also, because of the cosmetic advantage through laparoscopic surgery, more patient satisfaction is achievable.

While the risk of developing a recurrence in the abdominal wall is greater in small incisions of laparoscopic surgery than in open surgery [6], there have also been reports of recurrences in the laparotomy incision scar [18] [19]. Interestingly, the disease-free interval from the primary treatment in endometrial cancer patients with laparotomy wound recurrence was a mean of five years [18] compared to the port-site metastasis recurrences in patients undergoing a laparoscopic surgery where there is a mean time to PSM of 15.3 months [4]. In general, the risk of wound metastasis in endometrial cancer patients is not thought to be greater in laparoscopic surgeries compared to open procedures [4] [16] and that in both approaches there are no specific risk factors that could predict metastasis [4].

\subsection{Hypothesis of the Mechanism for Port Site Metastases}

There are several hypotheses how PSM can occur. These include: wound contamination, pneumoperitoneum, and immunosuppression due to the carbon dioxide $\left(\mathrm{CO}_{2}\right)$.

Wound contamination: The extraction of the cancerous specimens through a small port-site incision leads often to a carbon dioxide leakage during the extraction. This can promote free tumor cell movement, which has a high propensity of implantation in the traumatized tissue of the wound [20]. It is also possible that due to the dissection and the extrication of instruments that are contaminated with tumor cells, a wound contamination can occur.

Pneumoperitoneum: To distend the abdomen and visualize the viscera, $\mathrm{CO}_{2}$ is used as the insufflation gas during the laparoscopy. It is colorless and rapidly absorbable [21]. Unfortunately the high pneumoperitoneal pressure can stimulate movement of free peritoneal tumor cells, or it may dislocate tumor cells from viscera into 
the peritoneal cavity [22]. The "chimney effect" occurs due to the pressure gradient of the peritoneum. The gradient leads to an outflow of gas with possible floating tumor cells through the trocar or port site [23]. The "chimney effect" stimulates tumor cell implantation at the port site. The subsequent healing process leads to scar formation with the presence of entrapped tumor cells [24].

Immunosuppression: In a mice model and in a human experiment, it had been shown that in the laparoscopy, using carbon dioxide pneumoperitoneum decreased the immune mediators through TNF-alpha inhibition of the peritoneal macrophage (mice model) [25]. This caused a significant decrease in lymphocytes and cytokines during the early postoperative period before returning to normal levels (human experiment) [26]. This transient immunosuppression may promote the migration of tumor cells to the trocar site wound during laparoscopic surgery.

\subsection{Preventive Measures}

Even though there is no strategy proven to reduce the risk of PSM, there are several preventive measurements suggested. These include routine irrigation of the port sites [3] [6] [14] [27] [28] suturing of the peritoneum and of the fascia [3] [27], using a protective extraction bag to prevent wound contamination from resected malignant specimens [27] [29], occlusion of the fallopian tubes with clips or coagulation to prevent the spreading of tumor cell to the peritoneal cavity [7] [11], avoiding manipulation of the uterus [7], preventing high intra-abdominal pressure to avoid the "chimney effect" and deflating slowly [30] before removing the trocars [3], systematic resection of port-site scars and initiation of adjuvant therapies with no delay [27].

Even in an early low-grade endometrial cancer where these preventive measures were taken, PSM can occur [5]. In our case, some of the previous recommendations were practiced, including using an extraction bag.

Nevertheless, it was not sufficient to prevent the port-site metastasis. While high-grade histology and advanced stage are risk factors for recurrence, our patient had no surgical or histological risk factors such as high grade, the presence of positive peritoneal cytology, peritoneal studding or carcinomatosis.

Other currently un-measurable risk factors include tumor biology or genetic predisposition. We suspect that even with surgical attention to the prevention of cell spillage, there will always still be some risk of port-site tumor cell implantation from laparoscopy.

\subsection{Possible Reasons Why Our Patient Developed Port Site Metastases}

Our patient had a history of Hodgkin's Lymphoma and the possibility of residual immune suppression from her first malignancy. One hypothesis of why the PSM develops is immune suppression related to pneumoperitoneum, which potentially promotes unrestricted implantation of cancer cells. Another possible reason for the PSM occurrence in this patient might be associated with the surgical complications she has had with her hernia, and the widespread abdominal adhesions. The patient's severe adhesions were most likely a reaction from her splenectomy (associated with her Hodgkin's Lymphoma 20 years ago). A two hour-long extensive lysis of adhesions was performed to free up the omentum from the anterior abdominal wall. It is possible that the associated prolonged exposure to $\mathrm{CO}_{2}$ insufflation, causing the "chimney effect", stimulated tumor entrapment in the port sites.

\section{Conclusion}

The mechanism of PSM where there are no significant risk factors for recurrence is unknown. Several issues are raised by our case but are difficult to answer on the basis of the present published data. The main concern is whether PSM is iatrogenic or influenced by tumor biology and genetic factors. However, the benefits to laparoscopic surgery outweigh the risks as the incidence rate of PSM is low. Prospectively, multi-center data collection about PSM will lead to a better understanding of the risk factors and surgical techniques that increase risk of port-site metastasis.

\section{References}

[1] Tsuyoshi, O., Kuan-Gen, H., Renee, V., Ueng, S.H. and Lee, C.L. (2012) Unusual Trocar Site Metastasis in a Uterine Leiomyosarcoma after Laparoscopic Hysterectomy. Journal of Minimally Invasive Gynecology, 19, 252-254.

http://dx.doi.org/10.1016/j.jmig.2011.10.012 
[2] Zivanovic, O., Sonoda, Y., Diaz, J.P., Levine, D.A., Brown, C.L., Chi, D.S., Barakat, R.R. and Abu-Rustum, N.R. (2008) The Rate of Port-Site Metastases after 2251 Laparoscopic Procedures in Women with Underlying Malignant Disease. Gynecologic Oncology, 111, 431-437. http://dx.doi.org/10.1016/j.ygyno.2008.08.024

[3] Martinez, A., Querleu, D., Leblanc, E., Narducci, F. and Ferron, G. (2010) Low Incidence of Port-Site Metastases after Laparoscopic Staging of Uterine Cancer. Gynecologic Oncology, 118, 145-150. http://dx.doi.org/10.1016/j.ygyno.2010.03.011

[4] Palomba, S., Falbo, A., Russo, T. and LaSala, G.B. (2012) Port-Site Metastasis after Laparoscopic Surgical Staging of Endometrial Cancer: A Systematic Review of the Published and Unpublished Data. Journal of Minimally Invasive Gynecology, 19, 531-537. http://dx.doi.org/10.1016/j.jmig.2012.03.023

[5] Palomba, S., Falbo, A., Oppedisano, R., Russo, T. and Zullo, F. (2012) Isolated Port-Site Metastasis after Laparoscopic Surgery for Endometrial Cancer: A Case Report. Gynecologic Oncology Reports, 2, 16-17. http://dx.doi.org/10.1016/j.gynor.2011.11.006

[6] Kadar, N. (1997) Port-Site Recurrences Following Laparoscopic Operations for Gynaecological Malignancies. Obstetrics \& Gynecology, 104, 1308-1313. http://dx.doi.org/10.1111/j.1471-0528.1997.tb10980.x

[7] Muntz, H.G., Goff, B.A., Madsen, B.L. and Yon, J.L. (1999) Port-Site Recurrence after Laparoscopic Surgery for Endometrial Carcinoma. Obstetrics \& Gynecology, 93, 807-809. http://dx.doi.org/10.1016/S0029-7844(98)00308-1

[8] Faught, W. and Fung Kee Fung, M. (1999) Port Site Recurrences Following Laparoscopically Managed Early Stage Endometrial Cancer. International Journal Gynecological Cancer, 9, 256-258. http://dx.doi.org/10.1046/j.1525-1438.1999.09912.x

[9] Sanjuán, A., Hernández, S., Pahisa, J., Ayuso, J.R., Torné, A., Martínez Román, S., Lejárcegui, J.A., Ordi, J. and Vanrell, J.A. (2005) Port-Site Metastasis after Laparoscopic Surgery for Endometrial Carcinoma: Two Case Reports. Gynecologic Oncology, 96, 539-542. http://dx.doi.org/10.1016/j.ygyno.2004.10.018

[10] Wang, P.H., Yen, M.S., Yuan, C.C., Chao, K.C., Ng, H.T., Lee, W.L. and Chao, H.T. (1997) Port Site Metastasis after Laparoscopic-Assisted Vaginal Hysterectomy for Endometrial Cancer: Possible Mechanisms and Prevention. Gynecologic Oncology, 66, 151-155. http://dx.doi.org/10.1006/gyno.1997.4717

[11] Mäenpää, J.U., Nyberg, R. and Parkkinen, J. (2009) Port-Site Metastasis Following Laparoscopic Hysterectomy and Bilateral Salpingo-Ophorectomy for Endometrial Carcinoma. European Journal of Obstetrics \& Gynecology and Reproductive Biology, 143, 61-62. http://dx.doi.org/10.1016/j.ejogrb.2008.11.002

[12] Falanga, A. and Zacharski, L. (2005) Deep Vein Thrombosis in Cancer: The Scale of the Problem and Approaches to Management. Annals of Oncology, 16, 696-701. http://dx.doi.org/10.1093/annonc/mdi165

[13] Sørensen, H.T., Mellemkjaer, L., Olsen, J.H. and Baron, J.A. (2000) Prognosis of Cancers Associated with Venous Thromboembolism. The New England Journal of Medicine, 343, 1846-1850. http://dx.doi.org/10.1056/NEJM200012213432504

[14] Childers, J.M., Aqua, K.A., Surwit, E.A., Hallum, A.V. and Hatch, K.D. (1994) Abdominal-Wall Tumor Implantation after Laparoscopy for Malignant Conditions. Obstetrics \& Gynecology, 84, 765-769.

[15] Kruttwagen, R.F.P.M., Swinkels, B.M., Keyser, K.G.G., Doesburg, W.H. and Schijf, C.P.T. (1996) Incidence and Effect on Survival of Abdominal Wall Metastases at Trocar or Puncture Sites Following Laparoscopy or Paracentesis in Women with Ovarian Cancer. Gynecologic Oncology, 60, 233-237. http://dx.doi.org/10.1006/gyno.1996.0031

[16] Chua, T.C., Yan, T.D., Morris, D.L. and Sugarbaker, P.H. (2011) Port-Site Metastasis Following Laparoscopic Surgery. In: Shamsa, A., Ed., Advanced Laparoscopy, Chap. 11, InTech. http://www.intechopen.com/books/advanced-laparoscopy/port-site-metastasis-following-laparoscopic-surgery

[17] Spirtos, N.M., Schlaerth, J.B., Gross, G.M., Spirtos, T.W., Schlaerth, A.C. and Ballon, S.C. (1996) Cost and Quality-of-Life Analyses of Surgery for Early Endometrial Cancer: Laparotomy versus Laparoscopy. American Journal of Obstetrics \& Gynecology, 174, 1795-1800. http://dx.doi.org/10.1016/S0002-9378(96)70212-0

[18] Macias, V., Baiotto, B., Pardo, J., Muñoz, F. and Gabriele, P. (2003) Laparotomy Wound Recurrence of Endometrial Carcinoma. Gynecologic Oncology, 91, 429-434. http://dx.doi.org/10.1016/j.ygyno.2003.07.001

[19] Balbi, G.C., Cardone, A., Monteverde, A., Passaro, M., Montone, L., Rossiello, R., Visconti, S., Battista, M., Cassese, E. and Landino, I. (2006) Double Laparotomy Wound Recurrence of Endometrial Carcinoma. European Journal of Gynaecological Oncology, 27, 307-309.

[20] Tseng, L.N., Berends, F.J., Wittich, P.H., Bouvy, N.D., Marquet, R.L., Kazemier, G. and Bonjer, H.J. (1998) Port-Site Metastases: Impact of Local Tissue Trauma and Gas Leakage. Surgical Endoscopy, 12, 1377-1380. http://dx.doi.org/10.1007/s004649900862

[21] Menes, T. and Spivak, H. (2000) Laparoscopy: Searching for the Proper Insufflation Gas. Surgical Endoscopy, 14, 1050-1056. http://dx.doi.org/10.1007/s004640000216

[22] Moreira, H.J., Yamaguchi, T., Wexner, S., Singer, L., Zhao, R., Baig, M.K., Mack. J.A., Xiong, H. and Abramson, S. 
(2001) Effect of Pneumoperitoneal Pressure on Tumor Dissemination and Tumor Recurrence at Port-Site and Midline Incisions. American Surgeon, 67, 369-373.

[23] Hubens, G., Pauwels, M., Hubens, A., Vermeulen, P., Van Marck, P. and Eyskens, E. (1996) The Influence of a Pneumoperitoneum on the Peritoneal Implantation of Free Intraperitoneal Colon Cancer Cells. Surgical Endoscopy, 10, 809-812. http://dx.doi.org/10.1007/BF00189539

[24] Hirabayashi, Y., Yamaguchi, K., Shiraishi, N., Adachi, Y., Kitamura, H. and Kitano, S. (2002) Development of Port-Site Metastasis after Pneumoperitoneum. Surgical Endoscopy, 16, 864-868. http://dx.doi.org/10.1007/s00464-001-9121-7

[25] Ost, M.C., Patel, K.P., Rastinehad, A.R., Chu, P.Y., Anderson, A.E., Smith, A.D. and Lee, B.R. (2008) Pneumoperitoneum with Carbon Dioxide Inhibits Macrophage Tumor Necrosis Factor-Alpha Secretion: Source of Transitional-Cell Carcinoma Port-Site Metastasis, with Prophylactic Irrigation Strategies to Decrease Laparoscopic Oncologic Risks. Journal Endourology, 22, 105-112. http://dx.doi.org/10.1089/end.2007.9858

[26] Evrard, S., Falkenrodt, A., Park, A., Tassetti, V., Mutter, D. and Marescaux, J. (1997) Influence of $\mathrm{CO}_{2}$ Pneumoperitoneum on Systemic and Peritoneal Cell-Mediated Immunity. World Journal Surgery, 21, 353-357. http://dx.doi.org/10.1007/PL00012252

[27] Ramirez, P.T., Wolf, J.K. and Levenback, C. (2003) Laparoscopic Port-Site Metastases: Etiology and Prevention. Gynecologic Oncology, 91, 179-189. http://dx.doi.org/10.1016/S0090-8258(03)00507-9

[28] Ndofor, B.T., Soliman, P.T., Schmeler. K.M., Nick, A.M., Frumovitz, M. and Ramirez, P.T. (2011) Rate of Port-Site Metastasis is Uncommon in Patients Undergoing Robotic Surgery for Gynecological Malignancies. International Journal of Gynecological Cancer, 21, 936-940. http://dx.doi.org/10.1097/IGC.0b013e3182174609

[29] Thomas Jr., C.G. (1961) Tumor Cell Contamination of the Surgical Wound: Experimental and Clinical Observations. Annals Surgery, 153, 697-705. http://dx.doi.org/10.1097/00000658-196105000-00008

[30] Wang, P.H., Yuan, C.C., Lin, G., Ng, H.T. and Chao, H.T. (1999) Risk Factors Contributing to Early Occurrence of Port Site Metastases of Laparoscopic Surgery for Malignancy. Gynecologic Oncologoy, 72, 38-44. http://dx.doi.org/10.1006/gyno.1998.5128 